\title{
A Standard for the Commissioning Process
}

\begin{abstract}
The demand for commissioning services for new-building construction projects is experiencing rapid growth. Commissioning $(\mathrm{Cx})$ is touted as being a qualityfocused process for ensuring the owner's project requirements (OPR) are met by design, final construction, and the operations of a building. To an owner this is just what is needed to receive a perfect building at occupancy. However, as many owners have realized, the $\mathrm{Cx}$ process does not guarantee the completed building will be what was expected. It should be pointed out that this is typically not caused by the $\mathrm{Cx}$ process, but the $\mathrm{Cx}$ process should or could have identified, in the early phases of the project, many of the issues that made it through to the completed building. There are a number of reasons why the $\mathrm{Cx}$ services received may not be optimal. Often it is poor communication and the transfer of knowledge between project teams. Cx should and can facilitate both communication and the transfer of knowledge from phase to phase. An adaptation of the quality function deployment (QFD) four-phase model can accomplish this by filling the gaps among the major $\mathrm{Cx}$ activities and provide a standard approach to the process. The four-phase model effectively links each of the $\mathrm{Cx}$ activities to each other and back to the OPR, providing a method for improved communication and knowledge transfer. This paper investigates some potential reasons for inconsistent $\mathrm{Cx}$ services, presents an argument for the need of a $\mathrm{Cx}$ standard, and proposes a potential standard.
\end{abstract}

Keywords: construction, engineering management, quality, commissioning

\section{Introduction}

Many potential new building owners do not know what

Manuscript received October 30, 2014; accepted January 15, 2015

William L. Gillis, Elizabeth A. Cudney $(\bowtie)$

Engineering Management and Systems Engineering Department, Missouri University of Science and Technology, Rolla, MO 65409, USA

Email: cudney@mst.edu commissioning $(\mathrm{Cx})$ is, more so for those that have not constructed a new building. They may be introduced to the concept for the first time by the architect they have selected to design their building. They will certainly be exposed to $\mathrm{Cx}$ if they have decided to pursue Leadership in Energy and Environmental Design (LEED) certification. But actually, many owners that have contracted $\mathrm{Cx}$ services for their own buildings and have experienced the process might still not fully know what $\mathrm{Cx}$ is or at least what $\mathrm{Cx}$ should have been. Doty (2007a) explained that $\mathrm{Cx}$ should protect the owner's interest at each stage and fill gaps left from cost pressures in the design and construction methods. The core concepts of $\mathrm{Cx}$ are: (1) identify the intent of the work and how the goals will be met; (2) provide early detection and intervention of issues; (3) train operation staff; (4) prepare maintenance activities for sustainability; and (5) quantify the $\mathrm{Cx}$ benefits. The goal is to detect issues early using sampling techniques with a primary purpose of correcting systemic problems which would become long-term and costly.

Doty (2007b) also expressed that the owner support of the process is essential for success. For those owners who have experienced $\mathrm{Cx}$ and still do not know what the $\mathrm{Cx}$ process should have provided, it is possible the necessary owner support was missing from the project. It is also possible they had no idea they should have been involved in the $\mathrm{Cx}$ process. What $\mathrm{Cx}$ is or should be is up for debate. There are differing philosophies about the process and how it should be administered. Many $\mathrm{Cx}$ organizations and professionals are working toward improving the process and ultimately that the process should be directed toward ensuring the owner will be delivered the highest quality building according to their budget, timeline, and other requirements. Obviously each project will have different parameters, but a satisfied owner at project end is the goal of the $\mathrm{Cx}$ process.

One difficulty faced by owners, especially those who have not contracted $\mathrm{Cx}$ services, is who and what should be asked for and expected. There is currently no standard for the Cx process; therefore, services can and will vary. A quick look at the available guidelines will shed light on the issue. 


\section{Overview}

\subsection{Cx definitions}

American Society of Heating, Refrigerating and AirConditioning Engineers (ASHRAE) Guideline 0-2005 defines the Cx process as: "A quality-focused process for enhancing the delivery of a project. The process focuses upon verifying and documenting that the facility and all of its systems and assemblies are planned, designed, installed, tested, operated, and maintained to meet the Owner's Project Requirements." (ASHRAE, 2005)

The definition is generally for new-building construction. Other $\mathrm{Cx}$ processes for purposes outside of new construction are defined by ASHRAE Guideline 0-2005 shown as follows.

Re-Commissioning Process: "An application of the Commissioning Process requirements to a project that has been delivered using the Commissioning Process. This may be a scheduled re-commissioning developed as part of an Ongoing Commissioning Process, or it may be triggered by use change, operations problems, or other needs."

Retro-Commissioning Process: "The Commissioning Process applied to an existing facility that was not previously commissioned."

Ongoing Commissioning Process: "A continuation of the Commissioning Process well into the Occupancy and Operations Phase to verify that a project continues to meet current and evolving Owner's Project Requirements. Ongoing Commissioning Process activities occur throughout the life of the facility; some of these will be close to continuous in implementation, and others will be either scheduled or unscheduled (as needed). Also see Continuous Commissioning Process."

Continuous Commissioning Process: "A continuation of the Commissioning Process well into the Occupancy and Operations Phase to verify that a project continues to meet current and evolving Owner's Project Requirements. Continuous Commissioning Process activities are ongoing for the life of the facility. Also see Ongoing Commissioning Process." (ASHRAE, 2005)

In different terms, Re-Commissioning is a process conducted on buildings that were commissioned during the original construction. This process may be scheduled to be conducted every three years for example. The goal is to bring the building systems back to optimal operating conditions. Retro-Commissioning is a process for buildings that were never commissioned. The goal is to discover the deficiencies a building has, whether it be degraded equipment, calibration problems, failed sensors, a sequence of operation and control issues, or the multitude of other possibilities, and recommend the necessary corrections for the building to be brought up to its optimal operating condition. Ongoing Commissioning is similar to ReCommissioning as it is a continuation of $\mathrm{Cx}$ and extends through the life of the building, but may occur at any time, not necessarily at predetermined intervals. The goal is to identify system degradation or changes sooner than ReCommissioning for quicker resolution. Continuous Commissioning is nearly identical to Ongoing Commissioning, but takes the advantage of technology for metering and monitoring of systems, so changes in system performance are identified quickly and can be remedied immediately. This is expected to keep repair and energy costs at a minimum.

Having an understanding of the other $\mathrm{Cx}$ processes is important, as they are all conducted on existing buildings and the original new-building $\mathrm{Cx}$, as discussed in this research, is the baseline for the future $\mathrm{Cx}$ work.

\subsection{Cx guidelines}

The Cx industry and organizations generally align with ASHRAE's definition of $\mathrm{Cx}$, with that though there are many different approaches to the practice. The following is a list of organizations that have published either guidelines or best practices for defining what $\mathrm{Cx}$ is and how to go about providing the service. These are all well respected organizations which have contributed to the improvement of the Cx practice but nonetheless have not come to an agreement on one standard method for delivering $\mathrm{Cx}$ services.

ASHRAE: ASHRAE Guideline 0-2005, the Commissioning Process.

Building Commissioning Association (BCA): New Construction Building Commissioning Best Practice. (BCA, 2011)

California Commissioning Collaborative (CCC): California Commissioning Guide: New Buildings. (CCC, 2006)

General Services Administration (GSA): The Building Commissioning Guide. (U.S. GSA, 2005)

AABC Commissioning Group (ACG): ACG Commissioning Guideline: For Building Owners, Design Professionals, and Commissioning Service Providers. (ACG, 2005)

National Institute of Building Sciences (NIBS): Provide a number of technical commissioning guidelines for specific building systems.

Each of these guidelines has variations based on the organization's business focus. Other technical commissioning guidelines, focusing on $\mathrm{Cx}$ of specific systems, have also been developed by ASHRAE and NIBS with Guideline 0 as a platform for the others (see Figure 1).

Figure 2 illustrates a simplified flow chart of the major $\mathrm{Cx}$ activities in the process proposed in ASHRAE Guideline $0-2005$. These activities should be expected by any owner requesting services.

The LEED 2009 of the U.S. Green Building Council (USGBC) for new construction guideline requires an abbreviated version of $\mathrm{Cx}$. Two levels can be achieved: first the prerequisite (required by every project) in its energy and atmosphere (EA) credit category, EA Pre- 


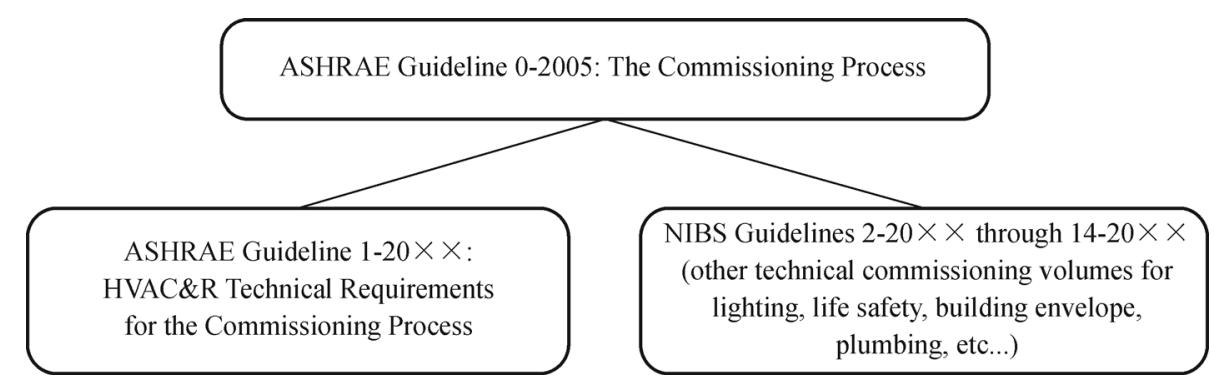

Figure 1. Commissioning guidelines.

Note: HVAC\&R is short for heating, ventilation, air conditioning, and refrigeration.

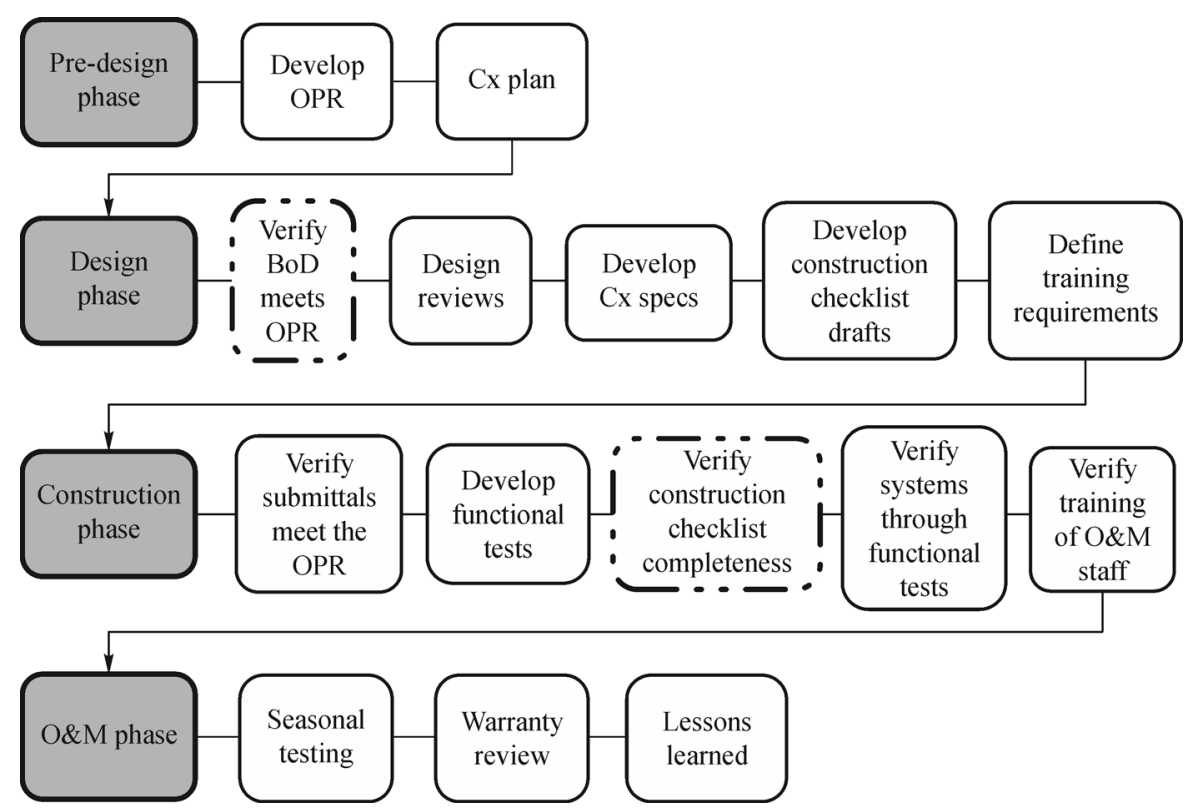

Figure 2. Flow chart of major $\mathrm{Cx}$ activities.

Note: OPR — owner's project requirements; BoD— basis of design; O\&M—operations and maintenance.

requisite 1, Fundamental Commissioning of Building Energy Systems; and for an opportunity for two additional points the project may attempt to meet EA Credit 3, Enhanced Commissioning (USGBC, 2009). Enhanced Cx requires that additional $\mathrm{Cx}$ activities are conducted and therefore the enhanced $\mathrm{Cx}$ process more closely meets the recommendations of ASHRAE Guideline 0-2005, but is still far from a full Cx process. Newsham et al. (2009) researched the question of whether the $\mathrm{Cx}$ process had been conducted properly; it is possible the question should have been whether the process was conducted completely. Again the question of what should be required arises.

The major activities are critical, but are only part of what the process needs to be. Serious consideration must be put into whom to contract to conduct the process. The current growth of $\mathrm{Cx}$ is increasing the demand for qualified providers, but what constitutes qualified providers is still in question.

\subsection{Demand growth for Cx services}

Mills et al. (2004) reported in a comprehensive study of the cost-effectiveness of building $\mathrm{Cx}$ that initiatives by utility companies, including $\mathrm{Cx}$ in some building codes, government requirements, and professional organizations, are contributing to growth, but the biggest driver at the time was the LEED certification process and the fact that LEED had a $\mathrm{Cx}$ requirement. LEED is continuing to drive growth. In 2006, 552 buildings had been certified under the LEED system (Turner \& Frankel, 2008). In November 2010, the USGBC reported that LEED certification had recently surpassed the one billion square feet mark worldwide with an additional six billion square feet currently registered for certification (USGBC, 2010). Other contributions to the growth have been created by states adding $\mathrm{Cx}$ to codes. California, Washington, and Massachusetts have $\mathrm{Cx}$ requirements in there building codes. Idaho public schools 
require $\mathrm{Cx}$. Oregon schools require $\mathrm{Cx}$ for certain building systems. With the rapidly growing industry the need for qualified practitioners is in demand and the supply is not keeping up with the demand (Tseng, 2005).

\subsection{Cx professional certification}

A professional certification typically indicates that an individual holds a certain level of competence in a given discipline. There are currently no laws which require a $\mathrm{Cx}$ certification for an individual to enter into a Cx services contract and many, with a wide range of abilities, background, and experience, are offering to provide $\mathrm{Cx}$ services. Some have or claim to have professional certification for providing such services. Ultimately, it is left to the discretion of the owner as to whether the potential $\mathrm{Cx}$ provider is qualified. Table 1 presents a breakdown of the organizations who are certifying $\mathrm{Cx}$ professionals, the designation, what is required for the certification, $\mathrm{Cx}$ training requirements, and certification renewal.
These are common certifications attained by $\mathrm{Cx}$ providers, but other certifications are available. Two organizations providing certifications not listed here are the National Environmental Balancing Bureau (NEBB) and Testing Adjusting and Balancing Bureau (TABB). Table 1 provides a summary of the current certifications, their sponsoring agency, and information on the certification requirements and format.

Table 2 provides further information on the range of experience required for certification. This is not an allinclusive list, rather the extremes for the multiple combinations ASHRAE and BCA require.

It can be seen that there is a wide range of requirements to qualify for the respective exams, different levels of education and/or training combinations, different exam formats, $\mathrm{Cx}$ project experience, and different renewal requirements. It is unknown which certification will provide the owner with the best $\mathrm{Cx}$ service provider. It is likely that as more individuals are certified, the requirements for certification will be tightened and become more difficult to meet. Opportunities for service providers to

Table 1

Cx Professional Certifications

\begin{tabular}{|c|c|c|c|c|c|}
\hline$\overline{\text { Certification }}$ & Organization & Cx experience required & Training required & Exam format & Certification renewal \\
\hline $\begin{array}{l}\text { Commissioning Process Management } \\
\text { Professional (CPMP) }\end{array}$ & ASHRAE & 3 projects & No & $\begin{array}{l}115 \text { questions } \\
2.5 \text { hours }\end{array}$ & 3 years, 45 PDHs \\
\hline $\begin{array}{l}\text { Certified Commissioning } \\
\text { Authority (CxA) }\end{array}$ & AABC Cx Group & 3 projects & No & $\begin{array}{l}100 \text { questions } \\
3 \text { hours }\end{array}$ & Annual fee only \\
\hline $\begin{array}{l}\text { Certified Commissioning } \\
\text { Professional }(\mathrm{CCP})\end{array}$ & $\mathrm{BCA}$ & 3 projects & Optional & $\begin{array}{l}125 \text { questions } \\
2 \text { hours }\end{array}$ & $\begin{array}{l}3 \text { years, proof of } \\
\text { continued } \mathrm{Cx} \text { work }\end{array}$ \\
\hline $\begin{array}{l}\text { Associate Commissioning } \\
\text { Professional (ACP) }\end{array}$ & $\mathrm{BCA}$ & None & Optional & $\begin{array}{l}125 \text { questions } \\
2 \text { hours }\end{array}$ & None \\
\hline $\begin{array}{l}\text { Commissioning Process Authority } \\
\text { Provider (Cx-AP) }\end{array}$ & UW-Madison & $\begin{array}{l}\text { 2-4 projects, square } \\
\text { feet, construction } \\
\text { cost minimums }\end{array}$ & 40 hours & $\begin{array}{c}4 \text { parts } \\
2.5 \text { hours }\end{array}$ & 5 years, fee only \\
\hline $\begin{array}{l}\text { Qualified Commissioning Process } \\
\text { Provider (QCxP) }\end{array}$ & UW-Madison & None & 40 hours & $\begin{array}{l}4 \text { parts } \\
2.5 \text { hours }\end{array}$ & Valid for 5 years \\
\hline
\end{tabular}

Note: PDH is short for professional development hours; UW-Madison stands for University of Wisconsin-Madison.

Table 2

Range of Professional Requirements

\begin{tabular}{lc}
\hline Commissioning certification & Range of professional requirements \\
\hline $\begin{array}{l}\text { ASHRAE's CPMP range of } \\
\text { professional requirements }\end{array}$ & Government-issued license as a professional engineer or architect with at least 3 years' facilities operation/ \\
management, construction, design, or consulting experience
\end{tabular}

High school diploma or equivalent or construction-related trades training or building operations training from a nationally or internationally recognized trade association with at least 10 years' facilities operation/management, construction, design, or consulting experience

BCA's CCP range of professional requirements
Four-year undergraduate degree or higher in a building science field (such as mechanical or electrical engineering, construction science, and construction) and a minimum of continuous 3 years as $\mathrm{Cx}$ provider in a lead role within the past 5 years

Two-year undergraduate degree in a non-building sciences field or high school diploma or general educational development (GED) and a minimum of continuous 3 years as a Cx provider in lead role within the past 5 years and a minimum of 12 years of building-related experience 
improve their skill set are available and required by at least one of the certifying organizations. UW-Madison, BCA, ASHRAE, and others provide formal $\mathrm{Cx}$ training in one form or another. With these varying abilities of professionals, a standard method of the Cx process would provide a means for the owner to have a better understanding of what service they should expect.

\section{Review of Cx literature}

The depth of academic literature in the area of commissioning is shallow. Several journals frequently provide information regarding $\mathrm{Cx}$ but most are limited to short column type entries. There have been a few academics that have focused their research on the aspects of $\mathrm{Cx}$ process.

Early literature is primarily focused on what $\mathrm{Cx}$ is and how it can be an advantage to the owner. There are three key attributes to commissioning: (1) $\mathrm{Cx}$ is a process, meaning there is a flow of tasks with each supporting the previous; (2) it is about quality; and (3) the focus is on performance. Any deficiency can affect the entire building. If the deficiencies are remedied, the owner might expect to see improvements in occupant comfort and productivity, energy and operating cost, indoor environmental quality, system and equipment reliability, building operation and maintenance, worker productivity, and market resale value (Tseng, 2005).

Doty $(2007 \mathrm{c})$ stated that prompt and accurate communication is required with an emphasis placed on early detection of systemic issues, but additional focus should be placed on quality deliverables to the future phases. Many of the deliverables are documentation to the operations and maintenance (O\&M) staff. The Cx process should start in predesign to reduce costs associated with late changes and the process requires much documentation throughout. There is no clear method for documenting the process and no method for comparing the costs versus savings ratio. Communication and documentation between the owners and designers is essential for $\mathrm{Cx}$ to work and the CxA facilitates both. The cost of the process is typically justified by the energy savings expected from a more efficiently operating building. Cx stems from the fact that new modern buildings contain many complex systems which require specialized expertise to verify they are all functioning properly together. With the need for these buildings to be delivered faster and cheaper, the life-cycle analysis is frequently overlooked (Nicholson \& Molenaar, 2000).

Many owners believed the process was an additional cost to the owner and it was seen simply as an extra expense which consumes valuable resources that could be spent on other project features. $\mathrm{Cx}$ practitioners and believers focused on selling the $\mathrm{Cx}$ process. Research shifted towards methods for calculating the savings achieved by the $\mathrm{Cx}$ process. Since no real cost was ever realized, the savings calculated were estimates based on professional experience. The major sources of savings are identified as first cost avoidance, future repair or replacement $\operatorname{cost}(\mathrm{s})$ of a defect, or reduced maintenance and energy cost(s). These savings are typically realized by identifying and protecting the OPR and the early detection and correction of issues (Doty, 2007c).

Energy saving is a convenient selling point for the process since it is expected to provide long-term savings. Commissioning a building does not ensure that all of the owner's energy goals will be met. An example of this involves a submittal review process in which a design team member approved a submittal for a fan coil unit and was either not aware or did not remember the aspects of the design which would require rejecting the product submitted. The incorrect unit would consume more energy. A lack of a communications interface was cited as a core issue for the incorrect approval (Ellis, 2009a). There is a relationship between commissioning and energy conservation, but one does not necessarily guarantee the other. Energy consumption is out of the design and construction teams' hands after occupancy. Much depends on the occupancy and the skills, tools, and available time of the O\&M staff to maintain proper system operations (Ellis, 2009b).

In order for the O\&M staff to have the tools to properly maintain the building, it is essential that the training and documentation are provided to them at turnover. Proper documentation begins with the OPR. Research suggests that $25 \%$ of buildings certified under LEED do not demonstrate the energy savings predicted by their designs (Turner \& Frankel, 2008). Potential reasons include not having a well-defined OPR, uncoordinated design, poor construction, and improper operation and maintenance. The design phase $\mathrm{Cx}$ will carry the required long-term measures through the entire process well into the operations and maintenance phase. There is a need for a holistic approach to Cx (Enke, 2010). Enke (2010) stated that in his experience the design phase $\mathrm{Cx}$ provides "... clear and concise construction documents that typically reduce project risk significantly and contingency used for change orders, tighter contract bids, a more maintainable facility, and the systems and procedures necessary to achieve and maintain facility performance". If the building is wellcommissioned, the operator can focus on preventive maintenance rather than eliminating complaints.

Ye and Rahman (2011) also considered why buildings do not perform as intended and cited faulty construction and the loss of information between project phases. The loss of information is caused by inconsistencies between the parties at phase changes and can result in project delays, poor quality, and increased cost. They suggested a need for research which looks at the project from the end backwards, meaning from the occupancy phase upstream to 
construction and beyond. A high level of interaction between all parties is essential through the life-cycle of the project.

It should be pointed out that the project life-cycle literally extends to a point in time when the building is razed. $\mathrm{Cx}$ is a multi-stage process which does not end at building occupancy. Verifying the building systems are performing as they were designed and expected by the OPR is only the first step in long-term success. Once the building is successfully commissioned, and complete and accurate documentation, as well as proper systems training for the O\&M staff, the building can go to the next level of performance. These deliverables provide the owner with a baseline for continuous improvement (Ellis, 2008).

Complete and accurate project documents from predesign through O\&M are critical to all team members. Ellis (2009c) noticed a trend of design documents being issued for bid prior to design being complete. Explaining that no design is perfect and the design and construction process has methods in place for dealing with the imperfections, but imperfect and incomplete are completely different issues. The top reasons for this occurrence include the design team's belief that some incomplete design can be finished later without affecting progress or budget, the owner's inability to express project requirements, and to not delay the construction start date. Cx can identify the incomplete design aspects and clearly state to the owner what appears to be missing and the impact or risks involved without waiting for a complete design prior to bidding. The goal is full transparency for all involved.

The OPR, BoD, and systems manual (SM) are key documents in the $\mathrm{Cx}$ process. Barber (2008) described them as a necessary evil, but these documents are often seen as expensive and not necessary, and therefore these invaluable tools are under used. They facilitate effective $\mathrm{Cx}$ and also provide critical information to the O\&M staff. Documenting the OPR has many valuable attributes, one of which is to minimize conflicting owner directives. Design teams often receive different priorities and expectations from groups within the owner's organization. The fully developed OPR requires the different groups to come to an agreement on common functional requirements. The BoD is then the confirmation from the design team that the OPR is understood and provides a description of how the requirements will be met with the design. The SM is likely the least understood and possibly the most important document. The SM focuses on the system operations and is intended to provide the functional intent, $\mathrm{BoD}$, configuration, the sequences of operation, and the operating characteristics of the as-built systems. This is the document that will guide the O\&M staff towards long-term sustainability (Barber, 2008).

The International Green Construction Code (IgCC), possibly the most comprehensive green building code to date, incorporates requirements for the $\mathrm{CxA}$ to provide a design review against the OPR and also a submittal review during construction. The constant verification builds quality into the project. $\mathrm{IgCC}$ also expresses the requirements of the SM, which should include systems narrative, the sequences of operations, control diagrams, and the set points recorded during functional testing. Wilkinson (2012) explained that this SM requirement is not sufficient and should also include the building description, the strategies for operations and control, maintenance procedures, and any metering locations. Wilkinson (2012) also expressed the need to better define an issues log required to keep the team informed of project progress.

Shakoorian (2006) performed a performance assessment of the building $\mathrm{Cx}$ process to determine which method of delivery would provide the best results. Delivery options were owner-led or designer-led. Five major performance factors were identified and investigated: communication, validation, collaboration, integration, and integrity. A panel of experts was surveyed using a Delphi study. The study pointed out that the communication performance measure was very poor for each delivery method and suggested a more rigorous investigation into the communication issues to improve communication within $\mathrm{Cx}$.

\section{Literature discussion}

From the previous research and literature, some common themes appear. First, the Cx process is the most effective if it begins in the pre-design phase. This provides an opportunity for the CxA to assist with the OPR development. The OPR is considered critical to a smooth project. The Cx goal is to ensure the OPR is met by design and construction and that all systems are functioning as expected. Energy saving is a selling point for the process but the savings are not always achieved. This is often due to the O\&M staff not receiving the needed training and/or documentation at building turnover. The focus of the literature appears to be at the front and back ends of the project. The common thread across all phases of the project is poor communication. Given the varying guidelines, capabilities of the potential $\mathrm{Cx}$ providers, the current and expected growth and demand for $\mathrm{Cx}$ services, a standard methodology for connecting each of the $\mathrm{Cx}$ activities within the process back to the OPR is needed.

The OPR and BoD are considered living documents and are subject to change. In Figure 2, two activities, "verify BoD meets OPR" and "verify construction checklist completeness", are typical points in a project when the $\mathrm{OPR}$ and $\mathrm{BoD}$ are frequently required to change. Late in pre-design phase or early in design phase the design team provides the $\mathrm{BoD}$ to the owner for review. If the $\mathrm{BoD}$ and OPR do not align well then it must be determined which document or both must change. To make an informed decision as to whether to allow the change it must be 
analyzed for how it will affect the OPR. The same holds for proposed changes during construction. The change must be traced back to the BoD and OPR to analyze how the change will impact other design criteria and OPR. Quick analysis is extremely important at this phase of the project. Hurried decisions are often made to keep the project on schedule without a complete understanding of how the decision will impact the project as a whole. A standard methodology utilizing an adapted quality function deployment (QFD) four-phase model can provide a means for tracing the proposed design changes back to the OPR. Figure 3 illustrates the proposed four-phase model.

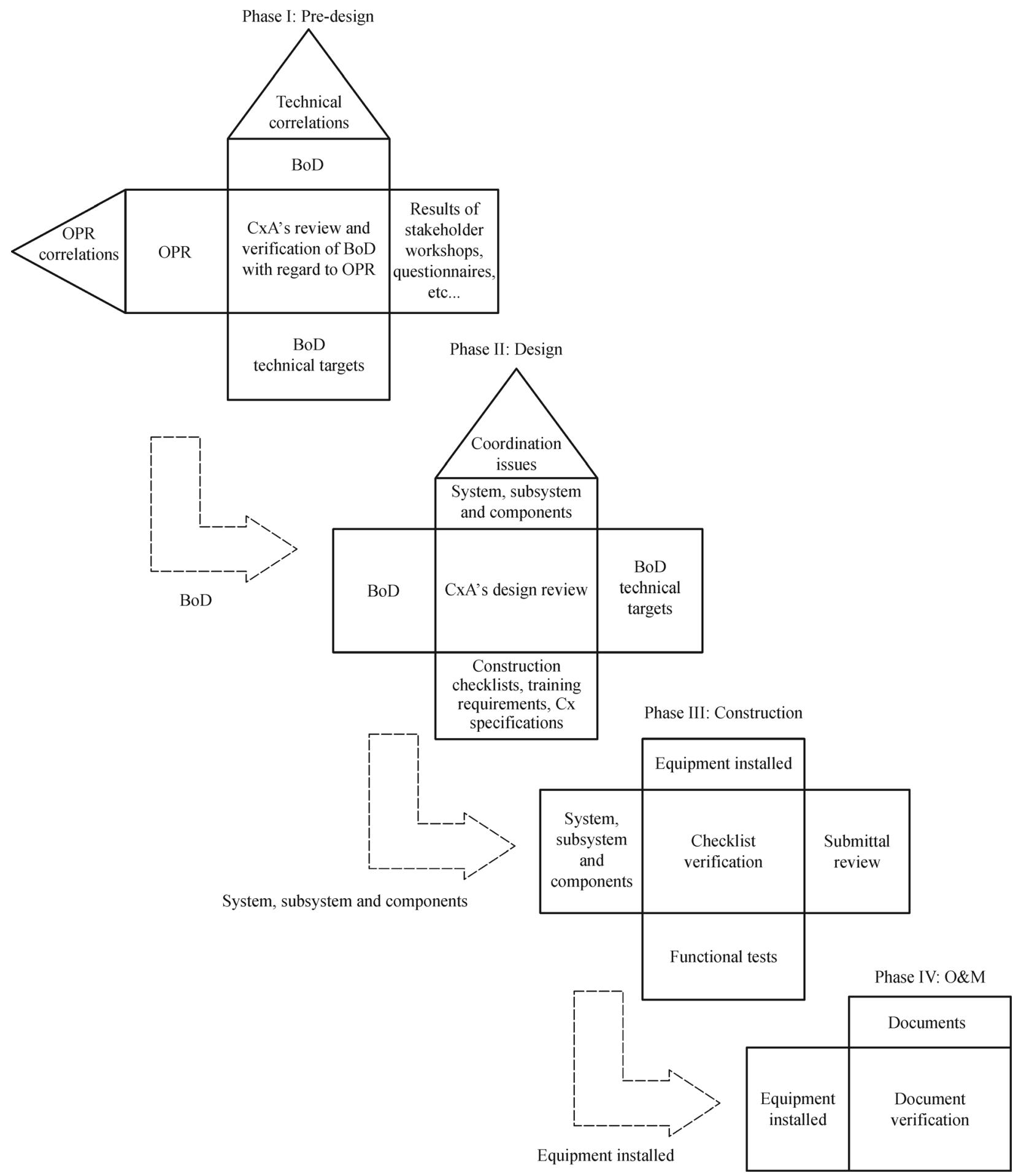

Figure 3. QFD four-phase model. 


\section{Methodology}

\subsection{Phase I: Pre-design}

The OPR is the start of the process. An accurate document will provide the design team with enough functional information about the building to develop their BoD for how they will meet all of the expectations. The first phase of the QFD model will compare these documents. Any deficiencies will be entered into the issues $\log$ and the owner will be notified. This begins the discussion or negotiation between the owner and the design team. Either or both documents may be updated depending on the discussion. This will likely require multiple iterations to come to an agreement, but the agreement is the goal. At the end of this phase the OPR and $\mathrm{BoD}$ should align and the design team can take both documents into the design phase.

Each item that was logged as an issue will be analyzed for its root cause. The analysis should uncover one of several causes. First, the necessary information was not provided in the OPR. This may be because the information was never considered or it was somehow left out when the final document was prepared. If the information was provided, the problem may be that the information was vague or inaccurately presented (one might argue that this is the same as not having the information at all). The design team may have misinterpreted the information and based their decisions on what they thought the correct information was. The design team may have made assumptions based on their experience or they did not address the requirement at all. Whatever the cause, the knowledge of why there was a problem will assist in improving the process by finding ways to improve the communication. Since this phase may require multiple iterations, there may be an opportunity for immediate improvement.

\subsection{Phase II: Design}

The next phase looks at the design review(s). Now the design will be verified against the $\mathrm{BoD}$. Typically the $\mathrm{CxA}$ will conduct one review of the design development documents and two reviews of the construction documents. The number of reviews and at what percentage of document completion would have been determined by the contract with the owner. Again any deficiencies or issues will be logged and reported to the owner. The issues will be traced back for root cause. The linked QFD model will allow a quick trace back to the $\mathrm{BoD}$ and OPR if necessary.

This may uncover a cause within the design document, BoD, or OPR. Any or all of the three documents may need to be revised. With this phase having multiple reviews there will be an opportunity to improve the communication for each later review. Other activities occur during this phase and will be captured in the QFD model, including the $\mathrm{Cx}$ specification development, construction checklist development, and construction coordination review (the roof of the model). The goal is to provide the most accurate and complete construction documents for the bidding process. This phase not only reviews the current work against the work of the previous phase but also begins preparing for the downstream customers, the contractors and the O\&M staff.

\subsection{Phase III: Construction}

The third phase is primarily about construction. The construction, by trades, will now be verified against the design. This will be accomplished using the construction checklists developed in the previous phase. The subcontractors will use the checklists during installation as a quality assurance measure. This does not eliminate the need for the subcontractor's internal quality assurance/ quality control processes. It is a measure to ensure certain aspects of the installation meet the OPR, mainly that there is easy access for any type of maintenance that will be required. The CxA will sample the completed checklists and verify accuracy during site visits. Again deficiencies or issues will be logged and investigated. A possible cause might be the coordination of the trades. The plumbers may have run their pipe in front of a variable air volume (VAV) access panel that is now blocked from removal. Now the issue analysis will have to determine why this happened and provide feedback for continuous improvement. Once again the linked QFD phases will allow the issue to be quickly traced back and any of the previous documents may require updating.

Other activities during this phase will include submittal review, functional test development, and training. Submittal review will determine if the materials and equipment proposed by the contractor align with all of the previous documents. If not, why. The functional tests will be used at the end of construction to verify the systems are functioning as expected. This phase again looks back at the previous phases for verification but also looks downstream and begins to prepare for the O\&M phase. An accurately built and functioning building, OPR, BoD, construction documents, functional tests, O\&M manuals, $\mathrm{SM}$, and training documents all come out of this phase and are the deliverables to the O\&M staff. Everything there is to know about this new building should be available for the O\&M staff to review in order to provide complete transparency of what, when, why, and how.

\subsection{Phase IV: O\&M}

The O\&M phase of the model is simply a checklist for gathering all of the necessary documentation for the O\&M staff at turnover. Having the complete documentation allows the staff to maintain and operate the building at 
optimal performance. The information contained within this documentation provides a method for continued communication between the O\&M staff and the occupants. One example of an opportunity to make use of the OPR and BoD documentation at building turnover is to develop a training session for the building occupants. Most times the occupants are not aware of the efficiency requirements that have been incorporated into the design and construction. Field experience has shown that the efficiency standard that is most often noticed by occupants and the cause of many calls to maintenance is the control of the heating, ventilation, and air conditioning (HVAC) system. Most have experienced a cold or warm period in their work space and have attempted to adjust the thermostat to improve the conditions. If it is cold in the office the thermostat is adjusted to a higher temperature and the expectation is that the space will become warmer. This is not an unreasonable expectation, but one that is often not realized. This may be caused by the HVAC control strategy. For example, ASHRAE Standard 55.1-2010, Thermal Environment for Human Comfort, informs the designer that most occupants will not be uncomfortable if the temperature is between approximately $70-76^{\circ} \mathrm{F}$. In the HVAC controls the set points for the temperature control are then locked to these temperatures. Meaning if the temperature is already $76^{\circ} \mathrm{F}$ and the thermostat is increased to a value above $76^{\circ} \mathrm{F}$, the system will not respond by making the space warmer. This frustrates the occupants that are feeling cold and frequently generates a call to maintenance with the complaint that the heat is not working. Other occupants in the area might appreciate the fact that the space is not getting any warmer. This scenario is also true for the opposite state when more cooling is desired.

If the OPR and BoD are clear and provide information as to why this control strategy was pursued, the occupants can be informed of this when they move in. With a bit of understanding as to how the system is designed to operate, the complaints may be reduced. The few occupants who prefer a temperature outside the set points will know to dress accordingly to personally adjust for their own comport before calling maintenance with a complaint. This is a result of simple communication that is typically not accomplished. The $\mathrm{Cx}$ process is about quality, but quality requires communication, particularly through documentation. Detailed and accurate knowledge and information must be transferred through the project so each team has the best opportunity to deliver what is expected of them.

In the previous example, if the information regarding the HVAC set points is not available, this is again a breakdown in the communication and transfer of knowledge in the documentation. As this information should be presented in the OPR and BoD, the trace back through the four-phase model would lead back to those documents. The cause of the failure for those entries would be investigated. This issue of course would have been identified before the O\&M phase as the set point information is required for HVAC controls programming during construction.

The purpose of $\mathrm{Cx}$ is to ensure the owner has been delivered a building that was designed as requested in the OPR and built and operated as designed. It comes down to how the owner feels at the end of the Cx effort and whether there is satisfaction. Much of this is subjective. Issues are the key to determining if this has been accomplished. Obviously, if hypothetically there were no issues during the project, one would expect that the owner would be satisfied with the end product and the project would be considered a success. But, of course looking only at issues as a total count is not sufficient. When an issue occurred (project phase), what it involved, and what it cost the owner above the original budget need to be considered. For any issue that is analyzed, traced back to the root cause, and provides feedback for improving the Cx process, this may do little to benefit the owner of the current project. With that though, if the analysis of issues is deferred to project end, any improvements to the process will certainly only help to improve the project of the next client.

The methodology will be evaluated based on issues throughout the Cx process. Each issue that is discovered needs to be analyzed for root cause. With an expectation that every issue is caused by a breakdown in communication somewhere in the process, this will provide feedback to a possible weakness in the methodology and an opportunity for improvement. When considering a document as the means of communication, there may be a breakdown in the information that was input, the preparation of the document, the review of the information, or the use of the information. Each of these will need to be considered when evaluating improvement options. Shakoorian (2006) presented a table which illustrated the relationship for each of the $\mathrm{Cx}$ documents, the team members who will provide input, prepare the document, review the document or use the information in the document, and which role they have with the document. The table was then used to identify which documents were the most important. As might be expected, the OPR ranked the highest. This indicates that this document should receive significant attention.

The accuracy of each document is of utmost importance to the downstream team or user. If the documents are not accurate, issues are certain to occur. Careful attention to inputs, the drafting or creation of the document, and any review(s) will improve the ability of the user to complete their work accurately. In the interest of the CxA providing continuous improvement, even if it only benefits the next client, the issues need to be analyzed as they are discovered and resolved. The primary focus of the analysis is to discover the cause of the communication breakdown and to uncover ways to improve the process, but the analysis should include other perspectives.

First is the cost, if any, to the owner, designer(s), or contractor(s) for not stopping this from becoming an issue 
in the first place. Nearly every issue will have some cost associated with it, such as money, time, labor, or even reputation. Typically the sooner issues are identified and resolved the lower the cost to resolve. The analysis should also consider the other direction. What is the savings associated with identifying and resolving the issue at this particular point in the project. In addition, it is important to consider the cost if the issue was not caught. Nicholson and Molenaar (2000) investigated the savings aspect of the CX process primarily to use as a point for selling Cx services to future project owners. Cost avoidance is certainly an important motivation for eliminating or reducing issues.

The goal with continuous improvement is to eventually contain the majority of the issues to the start of the project while the teams are attempting to bring the OPR and $\mathrm{BoD}$ into alignment. The resolution of these issues should not be costly.

\section{Case studies}

Two recent projects were selected for the review of $\mathrm{Cx}$ process as it relates to project issues and the opportunity to analyze the issues backwards through the phases for the discovery of root-cause. Issues were considered to be any request for information (RFI), change order (CO), warranty issue, maintenance work order (WO) submitted beyond the warranty period, and issues recorded by the $\mathrm{CxA}$ on the $\mathrm{Cx}$ issues $\log$. Table 2 contains the tabulated information gathered regarding project issues.

\section{Project data}

Building \#1. This was a four-year, multi-phase project to expand and renovate an existing building. The site consisted of two buildings, one to be razed and the other to remain for the renovation and expansion. The remaining building was a two-story, approximately $67,000 \mathrm{ft}^{2}\left(1 \mathrm{ft}^{2} \approx\right.$ $0.0929 \mathrm{~m}^{2}$ ), and used for classrooms, offices, and experimental and teaching laboratories. An attached three-story addition was added in the location of the razed building. The addition was approximately $90,000 \mathrm{ft}^{2}$, and primarily lab space with a few offices. Once the addition was completed, the offices and labs were relocated from the remaining building to the new section and a complete renovation of the old side was then conducted. Construction cost was \$26 million USD.

Building \#2. This was a major renovation project with complete demolition down to the shell. Most of the masonry interior partitions remained as the building programming did not change. The building is three-story with a full basement, $30,000 \mathrm{ft}^{2}$, of primarily research laboratories with a few offices on each of the upper three floors. Construction cost was \$46 million USD.

The same project manager, construction project manager, and director and assistant directors of operations were involved with both buildings from start to finish. During conversations with these owner's representatives regarding $\mathrm{Cx}$ of Building \#1, many negative recollections were expressed. Generally this project was not considered a success at completion. Consider the information provided in Table 2, much of the information that should have been documented and provided by the $\mathrm{Cx}$ provider was not located. It is unknown to the researcher if the information was originally provided and not properly filed or if the information was not provided at all. While reviewing the project files, no information regarding any $\mathrm{Cx}$ services was located including the original proposal for the $\mathrm{Cx}$ services, which would have identified what was actually expected of the $\mathrm{Cx}$ provider. It was pointed out by the construction manager that when issues were discovered, they were quickly remedied and did not likely end up on the issues $\log$ of the Cx provider. This was not the case for Building \#2.

During the Building \#2 project, it was explained to the $\mathrm{Cx}$ team, which included the construction manager and general contractor, that documenting the issues was not an attempt to point fingers or to point out substandard work but rather to document what occurred, how it was resolved, and to ultimately use the list to improve the process on the next project(s). This explanation was well received and most issues were added to the $\mathrm{Cx}$ issues log. The documented issues available for both projects were evaluated and traced back through the phases to determine if the issue could or should have been identified in an earlier phase of the project.

\subsection{Building \#1}

There were 312 total documented RFIs. The first nine RFIs were regarding details of the expansion joints between the

Table 3

Project Issues

\begin{tabular}{|c|c|c|c|c|c|c|c|}
\hline \multirow{2}{*}{ Building } & \multirow{2}{*}{ \# of RFIs } & \multicolumn{2}{|r|}{$\operatorname{Cos}$} & \multirow{2}{*}{$\begin{array}{c}\text { \# of warranty } \\
\text { issues }\end{array}$} & \multirow{2}{*}{ \# of WOs } & \multicolumn{2}{|c|}{ \# of Cx issues } \\
\hline & & Quantity & Cost ( $\$$ million USD) & & & Design issues & Construction issues \\
\hline$\overline{\# 1}$ & 312 & 173 & $\$ 3.9$ & -1 & $75^{2}$ & -3 & -3 \\
\hline$\# 2$ & 23 & 34 & $\$ 0.2$ & 3 & $\perp^{4}$ & 263 & 44 \\
\hline
\end{tabular}

Note: ${ }^{1}$ The documentation regarding warranties was unable to be located; ${ }^{2}$ issued during the second and third year, the majority being HVAC and lighting related, both systems have been a problem from building completion primarily due to the lighting controls and HVAC design and controls; ${ }^{3}$ documentation for Cx issues was not located; ${ }^{4}$ the building is just out of the warranty period and no WOs have been submitted. 
new addition and the remaining building. Three additional RFIs for expansion joints were submitted, with the last being 14 months after the first, again requesting details. The lack of these details should have been identified during one of the three or four $\mathrm{Cx}$ design reviews in the design phase of the project. At a minimum, the first nine requests should have prompted a full review of the expansion joint drawings and details. Ten RFIs were regarding lighting, mainly schedule deficiencies and electrical/control connection questions, were identified. The schedule deficiencies would have been identified during design reviews. It is unclear whether the electrical connection issues would have been discovered prior to construction. Sixty-three, or $20 \%$ of the total, RFIs identified were regarding the HVAC system. These span a full range of issues from coordination problems (ducts will not fit in space, interferences, penetration locations, etc.) and diffuser types to the hydronic piping for an air handler completely missing. The hydronic piping issue resulted in a $\$ 44,000$ USD CO during construction. Again, most of these would have been identified during a $\mathrm{Cx}$ design review while utilizing the roof of the design phase model to identify coordination issues and the development of construction checklists below the body of the matrix. Seven related to doors, with one for the lack of a door schedule in the drawings. Another was questioning electronic access which resulted in a $\mathrm{CO}$ of about $\$ 245,000$ USD. This is an OPR that should have been captured prior to the architect's programming and definitely should have been identified as to whether the $\mathrm{BoD}$ addressed this OPR during the pre-design phase.

The number of COs was high at 175 for a cost of about \$3.9 million USD. Just over \$1,000,000 USD was caused by a project delay that would not have been impacted by the $\mathrm{Cx}$ process. Along with the two COs mentioned previously in the RFI discussion, a couple of standouts were identified. First is changes to the electrical one-line drawings to correct discrepancies at a cost of about $\$ 70,000$ USD. Second is to move the generator and associated wiring at the project phase change for a cost of about $\$ 99,000$ USD. Both of these would have been identified in the $\mathrm{Cx}$ design review.

As identified in Table 2, the warranty issues and issues $\operatorname{logs}$ from the Cx provider, for both design and construction phases, either do not exist, were never received by the owner, or have been misplaced. Either way, these important documents are not available and indicate a serious breakdown in the process.

The WOs during the two-year period after warranty identify multiple issues which should have been captured during the Cx process. Firstly, it should be noted that there were 75 WOs submitted, most of which involved the HVAC and lighting systems, and door locks. The various controls and control components appear to be at fault for the majority of the issues. As mentioned previously, the owner's representatives identified the HVAC and lighting systems as problematic from turnover to date. Though the documents are unavailable, the owner's representatives have identified that these systems had significant warranty calls and service. The root cause issues were never identified and resolved and the maintenance calls continued. Potential problems that the $\mathrm{Cx}$ process should have identified: the complexity of the control systems raising concerns of maintainability, the review of the proposed equipment, submittal reviews, O\&M staff training, functional testing, and the SM to explain how all of this works.

\subsection{Building \#2}

RFIs accounted for 23 of the issues. These included the requests of details for the installation of certain electrical, duct insulation, concrete walk elevations, and chilled water risers. These are relatively minor requests but these missing details should have been identified during the drawing reviews in the design phase.

There were 34 COs at a cost of about $\$ 200,000$ USD. The most significant included a $\$ 65,000$ USD CO to add data and voice over internet protocol (VOIP) capability to each space. This should have been picked up during predesign as an OPR and then ensuring it was addressed in the BoD. Another was a $\$ 38,000$ USD CO to add five additional new fume hoods to the labs. Again, this should have been picked up in the pre-design phase.

The design issues were recorded as comments for each drawing during the review. These comments totaled to 263 . Many of the comments were made by O\&M staff, which was included in the $\mathrm{Cx}$ review of the drawings. Most of the comments requiring changes to the design were able to be corrected without cost. The reviews with the O\&M staff were conducted after the start of construction. These changes should have been included in the OPR early in the pre-design phase. Again a breakdown in communication, but the results were not costly.

The $\mathrm{Cx}$ provider recorded 44 issues during construction, most of which were during the functional testing. Many of the issues involved the HVAC control and were presented to the owner as possible points of improvement. Some included the lack of alarms to notify O\&M of failures. These are simple control programming changes as each of the required sensors was available. Several involved the ballasts on specified emergency lights that were not functioning to turn on the lights during power outage simulations. Several other items were identified to not match the original design and were found to have been approved and changed by design and the owner, and had been documented in the as-built documents, but the $\mathrm{Cx}$ had not been notified. One change identified was the addition of a bypass pump for freeze prevention on the outside air coil. This change was made but never made the as-built drawings and was not brought to the attention of the O\&M staff. This became a failure point on the system 
during the first hard cold. It took some time to discover the issue through troubleshooting efforts. This was a failure of communication during the construction phase and leading into the O\&M phase. The Cx identified the issue and the designer was to update the as-built drawings but the information was never passed to the O\&M staff.

After the experience of Building \#1, this project was considered to be a success at completion. The $\mathrm{Cx}$ experience was considered to be much improved but there was still a desire to have a standard method to provide to potential $\mathrm{Cx}$ providers on future projects as a way to specify this is how it is expected to be done.

\section{Four-phase model example}

The following is an example of a proposed design change traced back to the OPR to identify the cause of the issue and the potential design impacts of the proposed change. This example assumed a change which was proposed in construction and involved the installation of a section of HVAC duct. This is a coordination problem in which electrical conduit, HVAC duct, and fire sprinkler lines are competing for the minimal space between the suspended ceiling and the structure above. The conduit and sprinkler lines have been installed and the proposed change is to reduce the size (the cross-sectional area of the duct would be reduced from the original design) of the duct as it passes through this area.

The installation of the duct can be traced back through the construction checklist, to the system, subsystem and components, then back to the design phase. At the design phase, the trace can be followed through the CxA's Design Review matrix to any associated $\mathrm{BoD}$ (there may be more than one). As a side analysis, the trace also looks up into the roof (coordination issues) for potential coordination issues. As it turns out, this coordination issue was identified in the design phase and the owner was notified by the CxA. Having used building information modeling (BIM) during design, the design team felt there was sufficient room for all components. Somehow this 3D modeling information did not get transferred to the general contractor and subs for use in construction. Continuing the trace back to the pre-design phase, it is found that a change of this BoD criteria will impact other BoD (identified in the roof, technical correlations) and those impacts will need to be analyzed. Now following the trace to the OPR it is identified that this $\mathrm{BoD}$ is connected to and may impact an OPR for low HVAC noise and another for efficiency. This is a LEED project and it is also found that a change in these OPRs may affect other LEED credits that are being attempted. Once all of the impacts are understood, the owner has some decisions to make, but can now make the decisions from an informed position regarding how many decisions will impact the project as a whole, rather than from the perspective of simply keeping the project on schedule.

\section{Conclusions}

There are many different approaches to the $\mathrm{Cx}$ process and the levels of ability among the $\mathrm{Cx}$ providers. A standard for the process is required. Utilizing the four-phase model provides a forward verification of the required information and documents to each phase of the project. This will provide any $\mathrm{CxA}$, regardless of their certification, $\mathrm{Cx}$ training, experience, and preferred guideline, a means to offer a consistent approach to all owners. Regardless of the project size and complexity, by virtue of constructing the model and tracking the required information, the project will have reduced issues by improving communication and knowledge transfer, and providing proper documentation to the O\&M staff at project end.

As previously mentioned, the successful $\mathrm{Cx}$ of a new building is only the beginning. Much is required for $\mathrm{Cx}$ to be considered successful but one key is the documentation to the O\&M staff. If the O\&M staff is prepared to operate and maintain in a sustainable manner, they will have greater opportunities to run at peak efficiency for the lifecycle of the building. Improving the knowledge transfer from the owner to the design team, from the design team to the general contractor and subs, and from the general contractor (GC) to the O\&M staff, provides a baseline for ongoing $\mathrm{Cx}$ and benefits back to the owner, becoming the full-circle of ensuring the OPR is met. The model also provides a means to trace issues back through the entire process to identify the root-cause and to allow the discovery of communication breakdowns and the opportunities for continuous improvement, along with the ability to understand the impact(s) of proposed design changes on the project as a whole.

The proposed methodology does provide a standard for conducting the $\mathrm{Cx}$ process and provides a platform for future academic research relating to improved project communication and documentation, the continuous improvement of major and minor $\mathrm{Cx}$ activities, and the deeper analysis of cost avoidance and the cost of quality. Until a standard methodology is implemented it will be difficult, if not impossible, to conduct this type of research.

\section{References}

AABC Commissioning Group. 2005. ACG Commissioning Guideline: For Building Owners, Design Professionals, and Commissioning Service Providers. Washington, DC, US: AABC Commissioning Group

American Society of Heating, Refrigerating and Air-Conditioning Engineers, Inc. 2005. ASHRAE Guideline 0-2005, the Commissioning Process. Atlanta, GA, US: ASHRAE, Inc.

Barber, K. 2008. Commissioning documents: Necessary evil. Consulting Specifying Engineer, 43(6), 51-57

Building Commissioning Association. 2011. New construction building 
commissioning best practice. Beaverton, OR, US: Building Commissioning Association

California Commissioning Collaborative. 2006. California commissioning guide: New buildings. California: California Commissioning Collaborative

Doty, S. 2007a. Quantifying commissioning benefits. Energy Engineering, 104(3), 20-35

Doty, S. 2007b. Simplifying the commissioning process. Energy Engineering, 104(2), 25-45

Doty, S. 2007c. Tips for applying commissioning. Energy Engineering, 104(3), 6-19

Ellis, R. T. 2008. Commissioning: Commissioning is just the start. Engineered Systems, 25(12), 18

Ellis, R. T. 2009a. Commissioning: Some solutions really aren't. Engineered Systems, 26(11), 20

Ellis, R. T. 2009b. Commissioning: Commissioning \& energy conservation. Engineered Systems, 26(10), 20

Ellis, R. T. 2009c. Commissioning and incomplete design documents. Engineered Systems, 26(5), 16

Enck, H. J. 2010. Commissioning high performance building. ASHRAE Journal, 52(1), 12

Mills E., Friedman H., Powell T., Bourassa N., Claridge D., Haasl T., \& Piette M. A. 2004. The cost-effectiveness of commercial-buildings commissioning: A meta-analysis of energy and non-energy impacts in existing buildings and new construction in the United States, LBNL56637. Berkely, CA, US: Lawrence Berkeley National Laboratory

Newsham, G. R., Mancini, S., \& Birt, B. J. 2009. Do LEED-certified buildings save energy? Yes, but.... Energy and Buildings, 41(8), 897905
Nicholson, M., \& Molenaar, K. 2000. Building commissioning: Ensuring quality and savings. In: K. D. Walsh, ed.Proceedings of Construction Congress VI: Building Together for a Better Tomorrow in an Increasingly Complex World. Reston, VA, US: American Society of Civil Engineers, 1074-1082

Shakoorian, A. 2006. Performance assessment of building commissioning process as a quality assurance system (Dissertation for the Doctoral Degree). Atlanta, GA, US: Georgia Institute of Technology

Tseng, P. C. 2005. Commissioning sustainable buildings. ASHRAE Journal, 47(9), S20-S24

Turner, C., \& Frankel, M. 2008. Energy performance of LEED ${ }^{\circledR}$ for new construction buildings. White Salmon, WA, US: New Building Institute. [2013-02-03]. http://www.usgbc.org/Docs/Archive/General/ Docs3930.pdf

U.S. General Services Administration. 2005. The building commissioning guide. Washington, DC, US: U.S. General Services Administration

U.S. Green Building Council. 2009. LEED reference guide for green building design and construction. Washington, DC, US: U.S. Green Building Council

U.S. Green Building Council. 2010. One billion square Feet of LEED certified green building projects worldwide. 2010-11-10[2011-0422]. http://www.usgbc.org

Wilkinson, R. 2012. Commissioning provisions of the international green construction code. Heating Plumbing Air Conditioning, 84(4), 26-31

Ye, K.M., \& Rahman, H. 2011. Attentiveness of building commissioning in the Malaysian construction industry. World Academy of Science, Engineering \& Technology, 80, 255-259 